\title{
METAPRAGMÁTICAS DE UM TESTE LINGUÍSTICO E IDEOLOGIAS LINGUÍSTICAS EM CONTEXTOS MIGRATÓRIOS
}

\section{METAPRAGMATICS OF A LANGUAGE TEST AND LANGUAGE IDEOLOGIES IN MIGRATION CONTEXTS}

\section{Letícia Leme da Cruz*}

UFG

\section{Joana Plaza Pinto** \\ $U F G$}

Resumo: O objetivo deste artigo é identificar, descrever e relacionar recursos metapragmáticos e ideologias linguísticas relacionadas ao teste linguístico CelpeBras em campos etnográficos online e offline. A metodologia etnográfica consiste em um levantamento de páginas do PEC-G e CELPE-BRAS ativas no aplicativo Facebook, a seleção de postagens, e entrevistas feitas com alunas do PEC-G de uma universidade federal. Para fundamentar as análises, são utilizados os conceitos de metapragmática, ideologias linguísticas, hierarquia linguística, padronização e mercado linguístico. Os resultados indicam que, além de movimentar um mercado linguístico com a venda de cursos preparatórios, o teste possibilita a propagação de uma ideologia linguística que apresenta a língua portuguesa apenas em sua forma padrão e compromete a experiência legítima de migrantes. Ao chegar ao Brasil, as estudantes encontram uma realidade linguística para a qual não foram preparadas pelo estudo da língua portuguesa para o teste. Existem ainda indícios que imprimem um caráter institucional ao teste, demonstrando que a finalidade predominante do teste é o ingresso em uma universidade brasileira.

Palavras-chave: Metapragmáticas. Ideologias Linguísticas. Migração estudantil. Teste linguístico. Celpe-Bras.

Abstract: The main goal of this paper is to identify, describe and interrelate
metapragmatic resources and linguistic ideologies connected to Celpe-Bras in
online and offline ethnographic fields. The ethnographic methodology consists of a
survey of Facebook pages on PEC-G and CELPE-BRAS, a selection of the pages'
posts, and some interviews with PEC-G students. In order to base the analyzis, the
concepts of metapragmatics, language ideologies, linguistic hierarchy, standardization
and linguistic market are used. The results indicate that, in addition to moving a
language market through the sale of preparatory courses, the test allows the spread
of a language ideology which presents the Portuguese language only in its standard
form and compromise the migrants' legitimate experiences. When the students
* Bolsista de Iniciação Científica (CNPq), Graduanda em Letras Português, Universidade Federal de Goiás (UFG), Goiânia, GO, Brasil. E-mail: leticialemecruz.9@gmail.com.

${ }^{* *}$ Bolsista de Produtividade em Pesquisa (CNPq), Professora Associada, Universidade Federal de Goiás (UFG), Goiânia, GO, Brasil. E-mail: joplazapinto@ufg.br. 
arrived in Brazil, they found a linguistic reality for which they were not prepared during the previous study of Portuguese for the test. There are also indications of the institutional character of the test, in demonstrating the predominant purpose of the test is to apply to a Brazilian university.

Keywords: Metapragmatics. Language ideologies. Student migration. Linguistic testing. Celpe-Bras.

\section{Introduzindo o problema e a base teórica}

O Certificado de Proficiência em Língua Portuguesa para Estrangeiros (Celpe-Bras), segundo apresenta o site do INEP ${ }^{1}$, é uma prova realizada no Brasil e em outros países com a função de avaliar e medir o nível e a competência linguística de um indivíduo em Língua Portuguesa Brasileira. É um exame oficial, elaborado e aplicado por uma comissão técnico-científica que é composta por professores(as) especialistas no ensino e avaliação da Língua Portuguesa Brasileira. Esse teste é exigido para a participação no Programa de Estudantes-Convênio de Graduação (PEC-G), que é uma ação do governo federal brasileiro que prevê o intercâmbio de estudantes estrangeiros(as) para o Brasil, a fim de ingressar em cursos da graduação e pós-graduação nas universidades brasileiras.

A investigação de dados sobre o exame Celpe-Bras nos documentos oficiais disponíveis nas plataformas governamentais indicou uma escassez de dados empíricos sobre os recursos comunicativos avaliados no teste, bem como seu caráter impreciso e lacunoso (DIAS; PINTO, 2017). Quando confrontados com dados trazidos em conversas informais com estudantes migrantes no âmbito do PEC-G, em momento de pré-campo da atual etnografia em andamento, foi possível acessar sutilezas não disponíveis oficialmente, perceber como variam as ações institucionais e não institucionais e as percepções que os sujeitos constroem sobre teste, língua, identidade e mobilidade.

Com base na observação de pesquisas anteriores, percebemos que tais testes - especialmente o Certificado de Proficiência em Língua Portuguesa para Estrangeiros (Celpe-Bras) -, ao invés de se configurarem como barreira à entrada do(a) migrante no país, como um critério de seleção, visam à padronização do uso “correto” da língua como forma de manutenção da divisão entre nacionais e não-nacionais, estratégia de mercado (por meio da comodificação do português em cursos preparatórios) e "vitrine" da cultura brasileira pelo globo (DIAS; PINTO, 2017).

Diante desses primeiros resultados, o foco para esse estudo de campo foi ampliado, resultando numa investigação de caráter etnográfico que interpreta as práticas linguísticas, tanto online quanto offline, em contexto de migração, como repertórios fragmentados e altamente móveis, performados por sujeitos reais na realidade social, possibilitando o cruzamento
${ }^{1}$ No site do Instituto Nacional de

Estudos e Pesquisas

Educacionais Anísio Teixeira, disponível em: $<$ http://portal.inep. gov.br/web/guest/ acoes-internacionais/ celpe-bras>. 
de aspectos macro e micro contextuais que enquadram a experiência de migrantes e indiciam diferenças e desigualdades de direitos sociais, econômicos, educacionais e, obviamente, linguísticos.

Para este estudo, adotamos a compreensão da linguagem em seu contexto social e o uso da língua como ação. Como é bem conhecido, ao longo do estudo dos atos de fala, Austin (1998) expõe níveis de ação, separando os enunciados em performativos, que realizam ações porque são ditos, e enunciados constativos, que realizam uma afirmação, ou seja, falam sobre algo. Ainda durante a discussão dos atos de fala, Austin desmistifica qualquer diferença entre enunciados performativos e constativos, pois observa que, no final das contas, todo enunciado constativo pode também ser performativo. Sendo assim a língua produz a ação. Se o que dizemos, age no mundo, então o que dizemos sobre o próprio dizer também produz ação. Sendo assim, consideramos como categoria teórica para análise neste artigo a metapragmática, que é o conjunto de recursos da ação reflexiva da língua que remete ao próprio uso (SIGNORINI, 2008), às codificações do contexto (POVINELLI, 2016) e, especialmente, às avaliações e racionalizações sobre as estruturas, os usos e as significações sociais dos usos (SILVERSTEIN, 1993). Signorini (2008, p. 119) define a metapragmática apontando suas interdependências dinâmicas com o espaço, o tempo e as demais dimensões sócio-histórico-cultural e político-ideológica dos usos linguísticos:

(...), as metapragmáticas da língua em uso num dado espaço/tempo são sempre heterogêneas e dinâmicas em diferentes graus porque resultam de sinergia de um aglomerado de fatores inter-relacionados, que vão desde a propriedade reflexiva da própria língua, associada às capacidades metalinguística e metacomunicativa dos falantes, até as dimensões sócio-histórico-cultural e político-ideológica das práticas de uso oral e escrito da língua e dos discursos sobre como são/como devem ser os usos linguísticos na interação social (discursos oficiais, científicos e de senso comum).

O contexto e a contextualização também são fundamentais, pois são as dinâmicas contextuais, entextuais, recontextuais, reentextuais, que serão determinantes para a observação ampla das metapragmáticas em uso (SILVA, 2014), e na descrição das ideologias linguísticas em torno dos testes linguísticos para migrantes. A circulação e o movimento de textos têm sido estudados por autoras e autores diversos que reconhecem que todo texto tem sua história natural, a precipitação de processos culturais contínuos (SILVERTEIN; URBAN, 1996) que fazem o texto mobilizar sua situação de produção imediata (contextuais), mover-se para novas situações de produção (entextuais), mobilizar novas situações de produção (recontextuais), e inserir novos textos em sua estrutura prévias (reentextuais). O texto, portanto, se movimenta no espaço e no tempo numa dinâmica que "não é tão somente um processo multimodal de textualização, mas sobretudo uma dinâmica de poder” (SILVA, 2014, p. 76), portanto, uma dinâmica ideológica. 
Quanto às ideologias linguísticas, é possível apresentá-las como dependentes de uma interpretação corriqueira da pragmática e da metapragmática, como afirma Blommaert (2014, p. 70):

Manipulamos continuamente e interferimos na língua com propósitos sociais e culturais. A metapragmática da língua organiza sua pragmática - seu significado na sociedade. E isso significa, então, que abordagens meramente voltadas para uma pragmática da língua correm o risco de aceitarem ingenuamente estruturas metapragmáticas comumente compartilhadas. Em outras palavras: uma linguística "normal” sempre corre o risco de arrastar consigo ideologias linguísticas disseminadas que dominam seu objeto.

Essas ideologias podem promover uma artefatualização da língua, transformando-a em objeto ou produto delimitado, como se uma língua pudesse ser vendida como um produto aos falantes. Se a língua for concebida como um artefato, existe aí um fato determinante para a estratificação de seu consumo, como se à língua enquanto “artigo de luxo” se tornasse argumento para a marginalização de quem não a domina ou não a pode comprar.

A artefactualização da língua não inclui as variedades desprestigiadas, desprezando as variedades populares e identificando apenas a variedade que pode ser comercializada. Esses tipos de hierarquias linguísticas não necessariamente utilizam critérios gramaticais, mas posições sociais e relações de poder entre falantes. Intrinsecamente associada à hierarquia linguística, existe a cultura da padronização, que Milroy (2011, p.51) define como algo primariamente com função de empregar uma determinada "uniformidade a uma classe de objetos”. Mesmo inicialmente não assumindo a padronização de uma variedade específica como ideologia, é necessário apontar que a padronização é fruto de uma ideologia linguística, pois uma variedade específica depende de uma “aceitação prévia” (MILROY, 2011, p. 55).

Milroy (2011) atribui à própria sociedade a possibilidade de aceitar a instauração de um padrão, situação que propicia mudanças linguísticas que abrem espaços subservientes ao mercado linguístico. A consciência de padronização mobilizada pelos falantes em função de interesses econômicos e sociais provoca, em alguma medida, a possibilidade de movimentação dos interesses mercadológicos, de forma que a existência de um padrão que não é acessível à maioria faz com que o mercado encontre brechas para atuar como propagador da variedade padrão mantendo interesses políticos e econômicos, assim a performatividade do padrão incita a artefactualizaçao da língua, articulando a comodificação da língua à padronização da mesma.

Buscando evidenciar ainda mais os processos de comodificação da língua, apontaremos ao longo da observação detalhada dos dados uma espécie de ponte entre o que Heller (2010, p.101) chama de "tensões contemporâneas entre ideologias e as práticas de linguagem”2, ou seja, como a ideologia sustenta e é sustentada pelas pragmáticas e metapragmáticas da língua.

2 Tradução nossa. 
Diante dessas ideias e do campo de pesquisa, é preciso evocar reflexões em torno da funcionalidade do teste de proficiência e acerca de como as metapragmáticas em torno do Celpe-Bras provocam situações que tendem a legitimar e manter ideologias linguísticas hegemônicas, assim como a manutenção da estratificação observada nas relações de poder.

Para evocar tais reflexões foi implementada uma metodologia que contempla dinâmicas multicontextuais a fim de conectar dados distintos, possibilitando assim uma compreensão do processo migratório que envolve o teste de proficiência.

Diante do problema e do quadro teórico, este artigo tem como objetivo geral discutir recursos metapragmáticos acionados sobre testes linguísticos em contextos online e offline. Esses recursos foram utilizados em ambientes virtuais frequentados por migrantes, que se submeteram ou planejam se submeter ao teste linguístico exigido como pré-requisito para os programas de mobilidade estudantil como PEC-G, e em entrevistas individuais sobre testes linguísticos realizadas com estudantes migrantes PEC-G de uma universidade federal.

Além de identificar os recursos metapragmáticos acionados por estudantes migrantes de universidade federais sobre os testes linguísticos a que se submeteram, objetivamos descrever as ideologias linguísticas acionadas e ainda relacionar os recursos metapragmáticos e as ideologias linguísticas observadas em ambientes virtuais.

Com tais objetivos, buscamos evidenciar o peso do teste e de seu preparatório no processo de migração, assim como explicitar a influência da língua e de suas avaliações e racionalizações na vida estudantil migrante no Brasil.

\section{Metodologia}

Este artigo tem origem numa pesquisa etnográfica mais ampla, que tem construído dados presenciais de observação, entrevistas e grupo de discussão. A mesma pesquisa identificou a disponibilidade das(os) participantes de interagir em ambientes virtuais diversos, como redes sociais e aplicativos de bate-papo.

A etnografia está sendo utilizada como uma perspectiva em que as etnógrafas, autoras deste artigo, não são apenas responsáveis por reportar, usando os termos de Polivanoc (2013, p. 62), mas de explicar como o material observado é constituinte de "teias de significado”. Sendo assim, somos participantes ativas da pesquisa independente do ambiente (interações presenciais e virtuais), construindo junto aos(às) estudantes a significação a ser analisada e interpretada.

Juntamente com os avanços no campo etnográfico, os estudos etnográficos virtuais têm crescido muito neste início de século XXI. Desde o 
trabalho de Christine Hine (2000), muitas pesquisas reconhecem a importância crescente dos ambientes virtuais para a geração de dados etnográficos (BARTON; LEE, 2017; BLOMMAERT, 2010; LENIHAN; HOLMES, 2017; LEPPÄNEN; KYTÖLÄ, 2017).

Além da questão da geração de dados, é importante assumir que as tecnologias de comunicação contemporâneas, em geral, e os ambientes virtuais, em particular, têm sido reconhecidos por estudos diversos como espaços de grande impacto nas formas interacionais (BARTON; LEE, 2017; BLOMMAERT, 2010; JACQUEMET, 2005; KEATING, 2015), na superdiversidade dos contatos linguísticos (BLOMMAERT; RAMPTON, 2011; VERTOVEC, 2007), na manutenção e diversificação do multilinguismo (LENIHAN; HOLMES, 2017; LEPPÄNEN; KYTÖLÄ, 2017) e no enfrentamento de espaços migratórios hierarquizados (BLOMMAERT; MALY, 2014; DALMAU, 2014).

Esse quadro de ampliação do potencial metodológico da combinação da etnografia face-a-face e a etnografia virtual, nos leva, neste artigo, à proposta de interpretação das entrevistas individuais em conjunto com o levantamento de páginas ativas no aplicativo Facebook, cujo tema é o teste de proficiência em Língua Portuguesa, o que possibilita dinâmicas de interação entre as(os) participantes diretos ou não, em horários “desencontrados”, com tempos e extensões diferentes para respostas, todas características presentes nos ambientes virtuais. Foram realizadas oito entrevistas na pesquisa entre os anos de 2016, 2017 e 2018. Dos vários temas das entrevistas, para este artigo focamos no tema do teste linguístico e nas avaliações metapragmáticas sobre o teste e seus resultados no percurso migratório do(a) estudante.

Para a geração do material empírico virtual, foi feito, no mês de dezembro de 2017, um levantamento de páginas ativas, no aplicativo Facebook, que continham informações diversas sobre o teste Celpe-Bras e sobre o PEC-G. E também a seleção de postagens que avaliam ou racionalizam o teste linguístico de alguma forma, configurando a observação das metapragmáticas envolvendo o teste de proficiência. O critério utilizado para selecionar as páginas ativas foi a data de sua última publicação, ou seja, são consideradas ativas apenas as páginas que publicaram em algum momento do ano de 2017, sem considerar o mês específico. Por causa da dinamicidade das redes sociais é possível que, realizando novamente o levantamento, sejam encontrados dados diferentes, haja visto que o levantamento foi realizado exclusivamente no mês de dezembro.

É importante ressaltar que nesse levantamento foram contempladas apenas páginas, e não grupos, hashtags ou demais ferramentas de circulação dentro do próprio aplicativo Facebook. A escolha por explorar apenas páginas se deu em função da acessibilidade: as páginas são abertas e sem restrições, já os grupos, por exemplo, dependem de uma participação do usuário e a 
maioria é fechado, mesmo que os grupos sobre PEC-G, principalmente, somem maioria em relação à quantidade de páginas.

A intenção é unir o material online que articula atos de fala amplos e públicos sobre o teste de proficiência, como são as páginas do Facebook sobre o Celpe-Bras e o PEC-G, e atos de fala em interação face-a-face (offline) de quem vivenciou o teste e a migração e já está no processo de avaliação da experiência passada, incluindo o teste. Assim, podemos compreender através dessa dinâmica multicontextual, as engrenagens das metapragmáticas sobre teste de proficiência, observando as ideologias linguísticas em cada situação específica.

Assim, os dados construídos ao longo da etnografia são presenciais e virtuais. Os trechos das entrevistas selecionados para análise constituem os dados presenciais utilizados, além das capturas de tela que foram adquiridas ao longo do levantamento e outras buscas feitas a páginas sobre Celpe-Bras e PEC-G.

Os resultados do levantamento mostraram que de oito páginas do PEC-G encontradas, cinco estão ativas, e de 28 páginas sobre o Celpe-Bras encontradas, dezoito estão em atividade. A função dessas páginas é basicamente divulgar informações sobre procedimentos de inscrição e a respeito do calendário de aplicação do teste, principalmente as páginas sobre PEC-G. Já as páginas sobre Celpe-Bras em geral divulgam informações sobre cursos particulares preparatórios para o teste linguístico. $\mathrm{O}$ que essas páginas investigadas têm em comum é a divulgação de informações diversas em torno do Celpe-Bras e do próprio PEC-G.

Todas as entrevistas analisadas seguem o mesmo roteiro, as entrevistadas contam sobre o processo de migração e como foi desde a escolha do país onde estudar, no caso o Brasil, até as burocracias que devem ser enfrentadas por migrantes quando já estão aqui. As entrevistadas fizeram um preparatório para o Celpe-Bras e o próprio teste, assim nossa análise foca nos trechos das entrevistas em que o teste é o assunto principal. Os nomes utilizados para identificar as entrevistadas são fictícios, tendo sido escolhidos por elas mesmas, assim a identidade pessoal das participantes é preservada. As entrevistas foram transcritas com base em uma adaptação das convenções de Mary Bucholtz (2000) e Rodrigo Borba (2014). As convenções de transcrição são parte do processo de transformação dos dados em áudio em um material escrito e as marcas escolhidas para serem destacadas na transcrição são aquelas que nos ajudaram a interpretar as sequências interacionais, com destaque para elementos de interação recorrentes nas entrevistas. As convenções são: 
Quadro 1: Convenções de transcrição

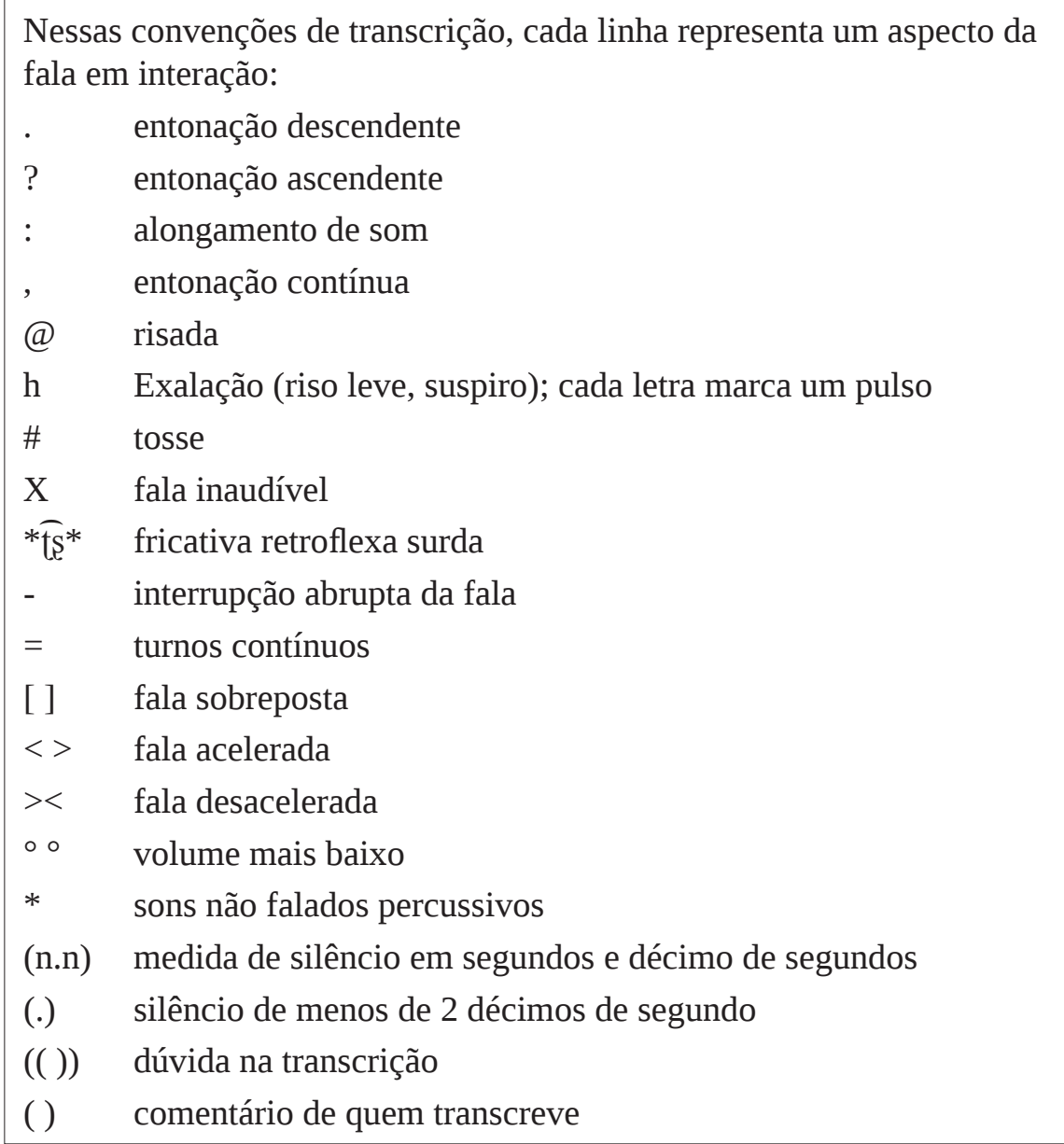

Fonte: Pinto (2016)

\section{Um teste de entrada institucional}

Ao longo do levantamento, notamos que as páginas sobre PEC-G são parecidas no sentido de publicarem informações burocráticas (datas e prazos, links para acesso aos editais, informações sobre os resultados) em relação ao Programa. Todas as páginas estão vinculadas a alguma instituição de ensino ou país em que o programa atua assiduamente. O objetivo dessas páginas, a partir de suas publicações e compartilhamentos, é divulgar o Programa e as burocracias que devem se tornar conhecidas pelos interessados em pleitear uma vaga em alguma instituição de ensino superior no Brasil. Algumas páginas ainda divulgam eventos que podem ser de interesse do(a) migrante que já está cursando graduação ou pós-graduação na instituição.

Já as páginas sobre Celpe-Bras têm um foco maior no momento anterior à migração. $\mathrm{O}$ conteúdo dessas páginas é também muito parecido, algumas 
divulgam informações sobre como se inscrever no PEC-G e principalmente sobre os meios de acesso à realização do teste. No entanto, a maior parte das publicações contém a divulgação de cursos preparatórios para o CelpeBras, além de compartilhar dicas de ortografia, dicas de como se preparar para o teste, apresentação de dados sobre os últimos exames aplicados, de forma que o conhecimento dessas informações colabore com o preparo para a próxima prova. A quantidade desse tipo de publicação evidencia aspectos do teste que remontam ideologias linguísticas de padronização e comodificação linguística, que impactam o processo de migração, conforme discutiremos adiante.

Após todas as buscas e observação dos dados, foi encontrado apenas uma postagem que não se encaixa nas características descritas acima. Trata-se de uma proposta de emprego que exige "fluência comunicacional e boa escrita no Português brasileiro e no Inglês”. Na publicação não existe nenhum item que se refere à necessidade do Celpe-Bras, mesmo sendo divulgada em uma página sobre o exame. Outro ponto importante a ser ressaltado é a descrição das páginas sobre Celpe-Bras usando a palavra “Educação”. Tal descritor metapragmático chamou atenção pela sua frequência, compondo o mesmo campo semântico com outras palavras que descrevem as páginas sobre Celpe-Bras, como "Escola”, "Escola de idiomas”, "Professor".

A partir dessas informações é possível pensar em outro aspecto muito presente nessa movimentação virtual promovida em função do teste de proficiência: seu caráter institucional, de forma que em todas as páginas existem indícios de que o Celpe-Bras está vinculado à função institucional de ingressar em uma universidade pública brasileira. Na Figura 1 é possível ilustrar essa característica dos descritores das próprias páginas. 
Figura 1: Print da página inicial da busca por “Celpe-Bras”

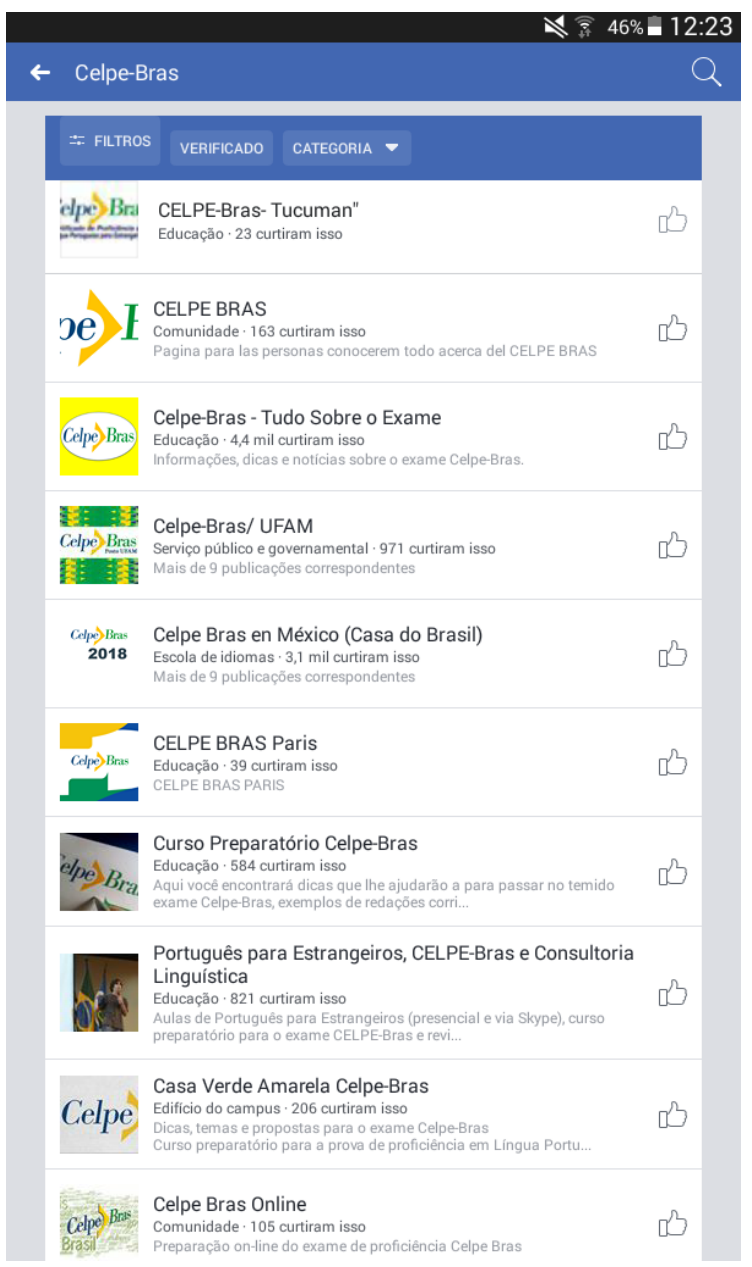

Fonte: Autoras (2018)

Ao confrontarmos esses dados virtuais com as entrevistas presenciais, podemos entender melhor que aspectos compõem as ideologias linguísticas do teste. A participante Erika, em entrevista realizada em 2017, relata seu curso preparatório para o Celpe-Bras e sua vinda para o Brasil, apresentando uma percepção muito crítica em relação aos recursos linguísticos em língua portuguesa. No Excerto 1, parte da narrativa de Érika sobre o curso preparatório para o teste, realizado em Brasília, a participante denota o aspecto institucional do teste, quando confirma que a maioria dos(as) alunos(as) do preparatório para o Celpe-Bras são potenciais alunos(as) PEC-G. O preparatório é observado como um “treino” para o teste, e não como um preparo para a interação cotidiana que o(a) migrante irá vivenciar no Brasil. 
Excerto 1

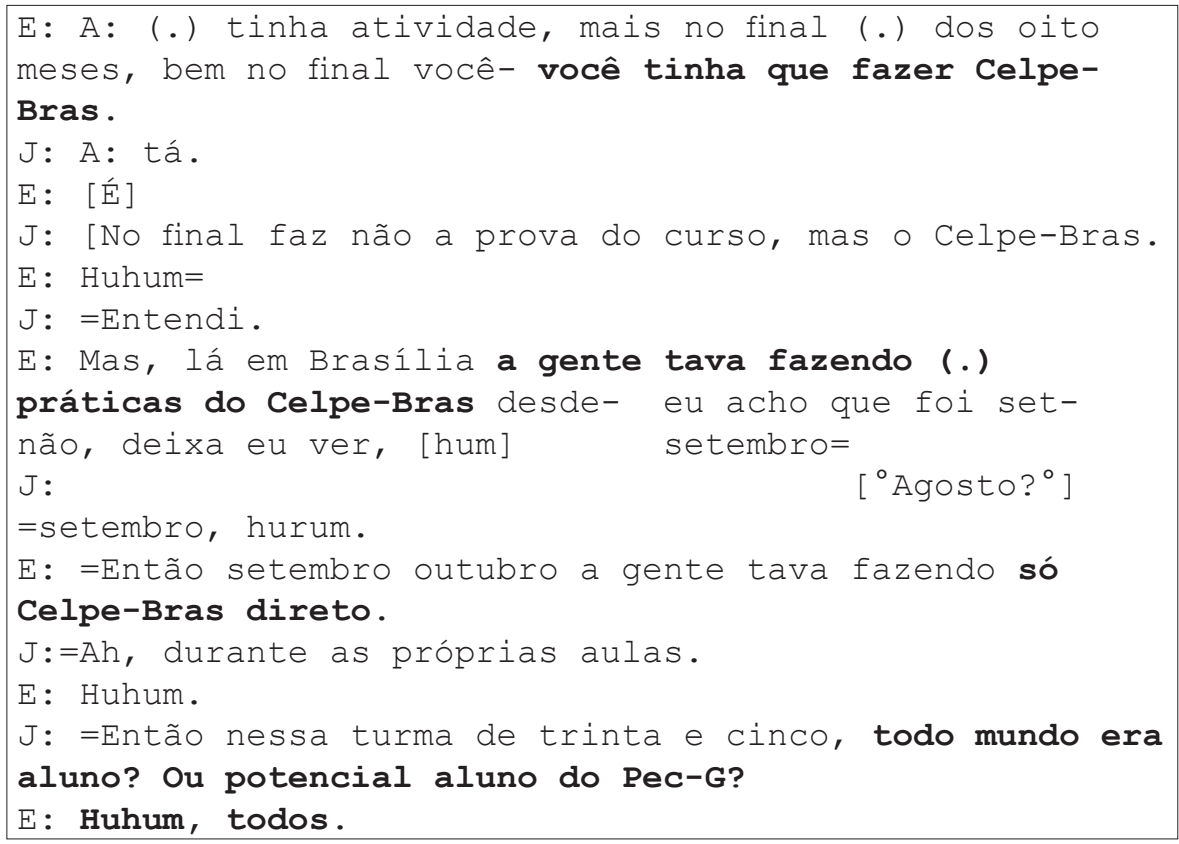

Legenda: J. = Entrevistadora. E.= Erika.

Fonte: PINTO (2017)

\section{Um mercado linguístico para um teste linguístico}

Os resultados nos levam a uma espécie de mercado linguístico, onde o teste de proficiência ocupa uma posição comodificada nas postagens, assumindo uma posição alta em uma hierarquia de mercado, gerando e movimentando compra e venda de cursos, manuais, dicas e outros objetos de consumo de língua. A maioria das páginas ativas são utilizadas para divulgar informações sobre cursos preparatórios sobre o teste, sendo esmagadora maioria desses preparatórios cursos particulares de língua portuguesa. A principal promessa dos anúncios é que o(a) participante será capaz de adquirir competência suficiente para aprovação no nível necessário exigido pelo teste para garantia da vaga no PEC-G.

Essa constatação ocorreu porque a recorrência de postagens contendo a divulgação de cursos preparatórios para o teste é numerosa, manifestando-se com o oferecimento de cursos preparatórios em várias modalidades, como cursos presenciais, cursos online, e até uma página nomeada "Português para Estrangeiros, CELPE-Bras e Consultoria Linguística”. Na Figura 2 é possível ilustrar como ocorre a divulgação desses cursos preparatórios para o Celpe-Bras, já que a maioria das páginas investigadas têm essas características, como espaços para contato e localização. Vale observar que, além de páginas com anúncios em português, é possível encontrá-los em outras línguas também. 
Figura 2 - Print com divulgação de aulas para o Celpe-Bras

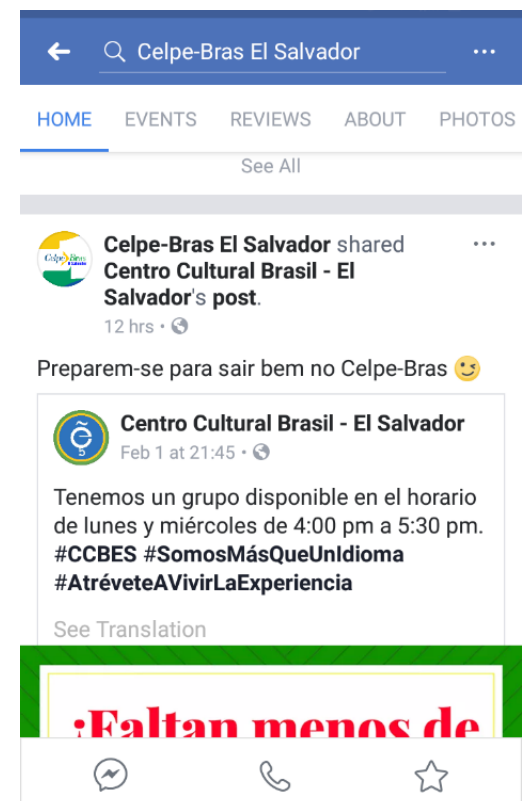

Fonte: Autoras (2018)

Nessa Figura 2 vemos a divulgação de grupo para preparação para o Celpe-Bras, exaltando a importância de um curso preparatório prévio para o teste, ao mesmo tempo em que divulga informações sobre o prazo que se aproxima. A articulação entre as informações objetivas explícitas e a importância implícita do preparatório torna naturalizada a codependência entre teste e curso de língua portuguesa.

Figura 3: Print de divulgação de simulado Celpe-Bras combinado com lembrete sobre a proximidade do exame

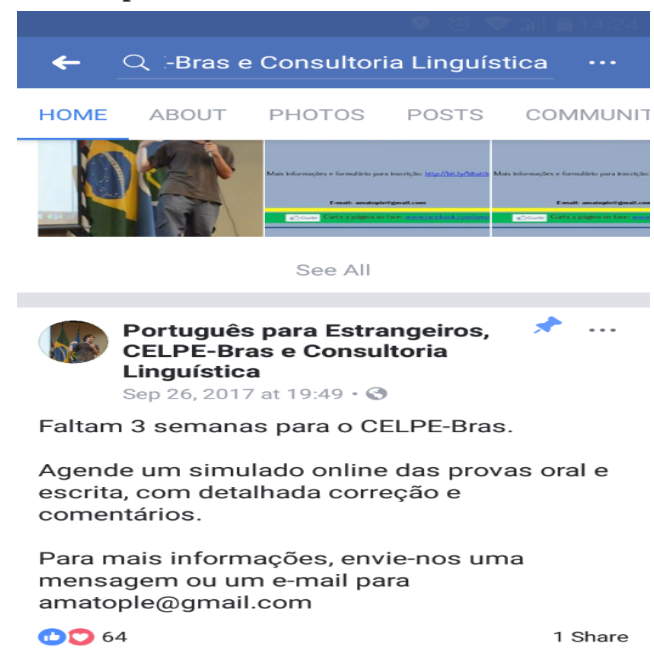

Fonte: Autoras (2017) 
A Figura 3 também demonstra como funciona o mercado movimentado pelo teste: o oferecimento de um “simulado” para o teste o objetifica e imprime no preparatório uma limitação que não contempla o uso da língua na interação. Nesses exemplos específicos, o mercado gira em torno do Celpe-Bras, ainda que possa servir amplamente ao interesse em proficiência na língua, ao turismo. Ou seja, o preparatório pode servir ao mercado de outras formas além de preparar para o Celpe-Bras, mas o fato é que o teste é central na movimentação deste mercado linguístico (HELLER, 2010).

Esse mercado influencia, em alguma medida, a experiência dos potenciais estudantes migrantes, porque ajuda-os a entender como funciona o teste que é exigido para que comprovem proficiência em língua portuguesa. No entanto, como será ilustrado nas seções seguintes, o preparatório para o teste não sustenta a necessidade comunicacional da(o) estudante durante a experiência empírica com a língua, assim a comodificação da língua, ensinada em função do teste e de forma fragmentada (limitando o ensino à estrutura do teste), propiciam a disseminação de certas ideologias sobre a língua portuguesa.

\section{Uma língua para o teste, outra para a vida}

Para pensar a experiência da(o) estudante migrante como um todo é necessário observar as etapas anteriores e posteriores à realização do teste de proficiência, que nesse trabalho é o ponto de conexão entre os dados online e offline. A partir de agora serão usadas apenas as entrevistas, de forma que as entrevistadas apresentem suas perspectivas sobre língua e aprendizado antes e após a realização do teste e de seu preparatório.

Um recurso metapragmático explícito pode ser observado na fala de Erika, quando avalia a rapidez e a intensidade de sua prática de aprendizado em língua portuguesa no curso preparatório para o Celpe-Bras em relação às práticas linguísticas no curso de graduação.

Numa parte da entrevista, Erika conta a experiência no início da graduação. A entrevistada avalia sua maior dificuldade ao chegar à Goiânia: o “sotaque goiano". Esse enquadre imprime ao teste e ao seu preparatório uma projeção de ineficácia, no sentido de tê-la preparado exclusivamente para variedades pressupostas como "padrão” para o aprendizado do português como segunda língua, enquanto seu encontro com uma das variedades locais na universidade de destino deixou-a "perdida". Ou seja, quanto mais os recursos linguísticos se desviarem da proposta padrão ministrada no curso preparatório para o Celpe-Bras, maior a dificuldade de compreensão. 


\section{Excerto 2}

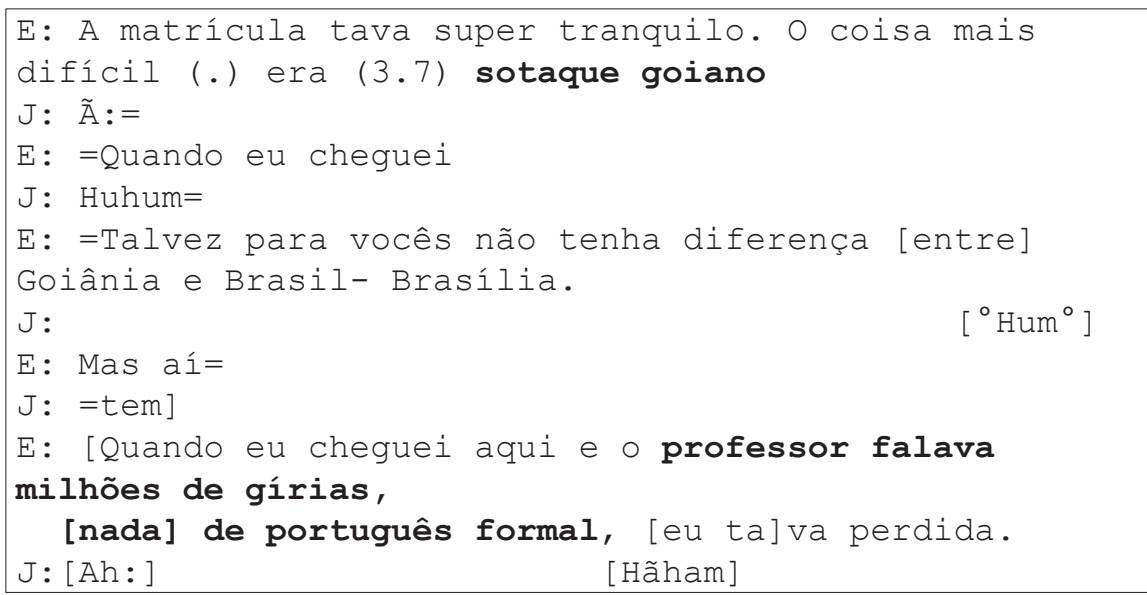

Legenda: J. = Entrevistadora. E.= Erika.

Fonte: PINTO (2017)

O que nos faz perceber essa contradição que envolve o teste não é somente a dificuldade de Erika naquilo que ela identifica metapragmaticamente como "sotaque goiano", e sim quando racionaliza que esse "sotaque" do professor, especificamente, não tinha nada do que chama de "português formal”. Os recursos linguísticos utilizados pelo professor ("milhões de gírias”, como avalia Erika) estavam muito distantes dos recursos que a entrevistada estava acostumada durante o curso. Esse dado nos leva a refletir sobre como o teste pode funcionar como um divisor de águas na vida do(a) migrante, pois ele(a) é preparado(a) para um conjunto de recursos linguísticos específicos, reconhecidos por Erika como “português formal”, enquanto os recursos linguísticos da vida cotidiana universitária não correspondem ao conjunto exigido pelo teste.

O próximo excerto de entrevista também retrata inequivocamente o limite do teste como medida de avaliação para uso futuro da língua portuguesa no Brasil, de forma que a entrevistada, tendo já vivido no Brasil antes do teste, assume a necessidade de realização de um curso específico para fazer a prova. A entrevistada é Vaska e sua percepção como aluna PEC-G confirma que o preparo e o próprio teste não estão em consonância com a realidade empírica a ser enfrentada pela estudante migrante.

No Excerto 3 transcrito adiante, a entrevistadora e Vaska falam sobre o processo para a realização do Celpe-Bras. Vaska está narrando a informação que recebeu de que poderia fazer o teste no Brasil e estudar por conta própria a língua portuguesa. Quando a entrevistadora pergunta se é obrigatório fazer um curso de português para o teste, Vaska confirma que não é obrigatório, mas avalia que sem um curso não é possível fazer a prova ("se não cê vai fazer prova como?”). A partir dessa fala é possível refletir sobre 
a extensão e efeito da ideologia linguística da padronização, já que o teste carrega uma marca, que evidencia e promove uma hierarquia linguística da “forma aceita” (MILROY, 2011).

\section{Excerto 3}

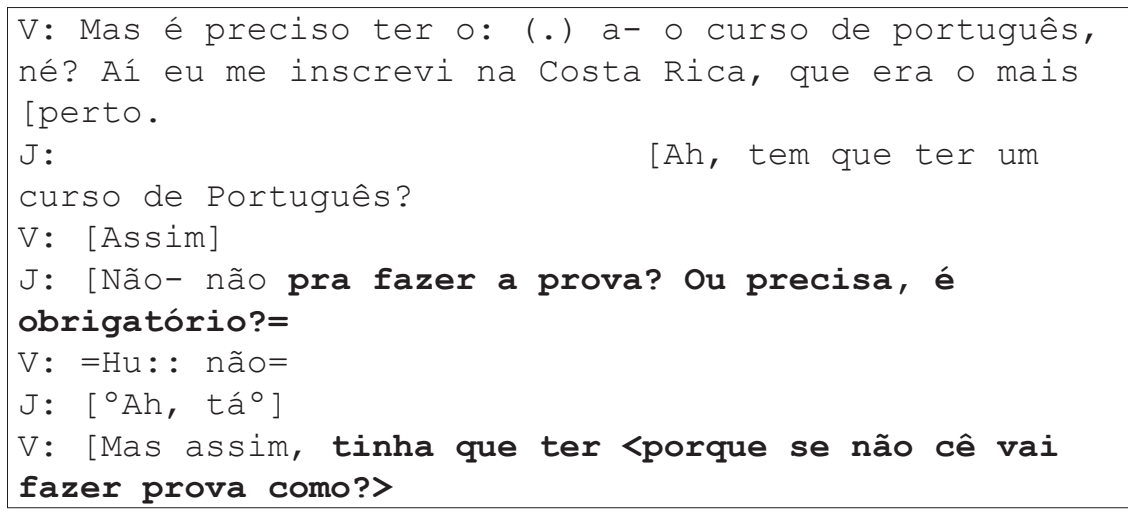

Legenda: J. = Entrevistadora. V.= Vaska.

Fonte: PINTO (2017)

A ideologia da comodificação da língua - enquadrada aqui como objeto de consumo estratégico para fins do teste - age nesse sentido como marca deixada pelo teste na vida do(a) migrante, ou seja, a ideologia está presente antes, naquilo que torna “óbvio” fazer o curso preparatório, mesmo que não seja "obrigatório”, e depois, na avaliação da sua própria prática linguística diante da língua objetificada (HELLER, 2010). Os dois excertos apresentados revelam que a experiência com o teste influi diretamente na metapragmática utilizada pelo(a) estudante migrante em sua avaliação da realidade pós-teste. Na fala de Erika fica evidenciada uma metapragmática explícita que expõe a diferença de avaliação de seu uso do português antes do teste e após o teste.

\section{Excerto 4}

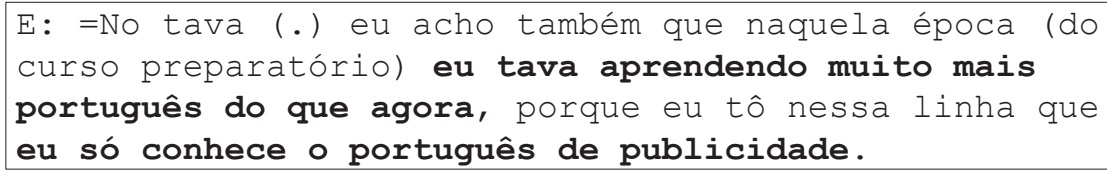

Legenda: J. = Entrevistadora. E.= Erika.

Fonte: PINTO (2017)

No Excerto 4, Erika sintetiza as dinâmicas circunstanciadas, multifacetadas e contraditórias das avaliações metapragmáticas das práticas linguísticas (PINTO, 2012; SIGNORINI, 2008): enquanto compara com as práticas linguísticas iniciais de sua graduação, o curso preparatório parece não ter ensinado a ela o suficiente (Excerto 2); enquanto ao comparar com 
o final da sua graduação (época da entrevista), o curso parece ter oferecido um conjunto de recursos linguísticos muito mais amplo ("eu tava aprendendo muito mais português do que agora”) do que a vida universitária (“eu só conhece o português de publicidade”).

\section{Conclusão}

Os resultados indicam que nem os cursos preparatórios nem o teste garantem um aprendizado de recursos linguísticos avaliados como suficientes pelas participantes. Essa avaliação de insuficiência na preparação para o uso da língua aparece sempre articulada com graus diferentes de comprometimento da experiência linguística das estudantes migrantes.

Além disso, o mercado linguístico em torno do teste se propõe a movimentar consumidores futuros do PEC-G e, também, consumidores não estudantis, embora, em nenhum dos dados levantados nas páginas online, o certificado de proficiência em Língua Portuguesa seja exigido em outros contextos migratórios além do estudantil.

As situações aqui apresentadas configuram o teste de proficiência como um sustentador de ideologias linguísticas que constituem uma hierarquia linguística, apagando práticas linguísticas variadas potenciais ao contexto universitário. Ao promover uma forma padrão em torno do teste, os agentes envolvidos no processo constituem uma estratégia de artefactualização da língua (BLOMMAERT, 2014) em produtos de ensino e avaliação, confirmando que o teste não caracteriza qualquer tipo de "barreira” para falantes de línguas estrangeiras (DIAS; PINTO, 2017), mas mantém ideologias que limitam e reduzem o português brasileiro a práticas linguísticas específicas.

O Celpe-Bras e os cursos preparatórios movimentam um mercado linguístico que constituem uma ideologia de língua padrão, no sentido de apenas vislumbrar a possível realidade interativa do(a) migrante, fato evidente na avaliação das nossas entrevistadas. Elas confirmam o papel do teste, funcionando como mais um dispositivo de padronização, na construção daquilo que Milroy (2011) chama de “aceitação prévia”, aqui explicitamente articulada com a comodificação da língua (HELLER, 2010) portuguesa no cenário internacional. As duas ideologias - a da padronização e a da comodificação das línguas - se integram nesse cenário.

É importante finalizar com uma reflexão sobre qual o peso desse processo para os(as) estudantes migrantes, como a língua pode tornar-se uma frustração a partir dessa mescla de experiências linguísticas contraditórias. Tal perspectiva confere uma aparência negativa ao Celpe-Bras que, na medida da vinculação institucional, tem um lugar de relevância no processo de migração estudantil, mas não considera os usos heterogêneos que compõem a realidade linguística da vida universitária no Brasil. 


\section{Referências}

AUSTIN, John. L. Performativo-constativo. In: OTTONI, Paulo. Visão performativa da linguagem. Campinas: Editora da UNICAMP, 1998. p.107-144.

BARTON, David; LEE, Carmen. Methodologies for researching multilingual online texts and practices. In: MARTIN-JONES, Marilyn; MARTIN, Deirdre (Ed.) Researching multilingualism: critical and ethnographic perspectives. New York: Routledge, 2017. p. 141-154.

BLOMMAERT, Jan. Ideologias linguísticas e poder. Tradução de Ive Brunelli. In: SILVA, Daniel N.; FERREIRA, Dina M.; ALENCAR, Claudiana N. de. (Org). Nova Pragmática: Modos de Fazer. São Paulo: Cortez, 2014. p. 67-77.

BLOMMAERT, Jan; JIE, Dong. Ethnographic fieldwork: a beginner's guide. Bristol: Multilingual Matters, 2010.

BLOMMAERT, Jan; MALY, Ico. Ethnographic linguistic landscape analysis and social change: A case study. Tilburg Papers in Culture Studies, n. 100, p. 1-28, jun. 2014.

BLOMMAERT, Jan; RAMPTON, Ben. Language and superdiversity. Diversities, v. 13, n. 2, p. 1-22, 2011.

BORBA, Rodrigo. (Des)aprendendo a "ser": trajetórias de socialização e performances narrativas no Processo Transexualizador. 2014,206 f. Tese (Doutorado em Linguística Aplicada) - Faculdade de Letras, Universidade Federal do Rio de Janeiro, Rio de Janeiro, 2014.

BUCHOLTZ, Mary. The Politics of Transcription. Journal of Pragmatics, v. 32, p. 1439-1465, 2000.

DALMAU, Maria Sabaté i. Migrant communication enterprises: regimentation and resistance. Bristol: Multilingual Matters, 2014.

DIAS, Ana Luiza K.; PINTO, Joana Plaza. Ideologias linguísticas e regimes de testes de língua para migrantes no Brasil. Revista Brasileira de Linguística Aplicada, v. 17, n. 1, p. 61-81, 2017.

HELLER, Monica. The commodities of language. Annual Review of Anthropologie, v. 39, p. 101-114, 2010.

HINE, Christine. Virtual Etnography. London: Sage, 2000.

JACQUEMET, Marco. Transidiomatic practices: Language and power in the age of globalization. Language\& Communication, n. 25, p. 257-277, 2005.

KEATING, Maria Clara. Desxenofobando: dinâmicas materiais e movimentos dos sentidos nas oficinas biográficas. In: LECHNER, Elsa (Org.). Rostos, vozes e silêncios da imigração. Coimbra: Almedina, 2015. p. $145-170$ 
LENIHAN, Aoife; HOLMES, Helen K. Virtual ethnographic approaches to researching multilingualism online. In: MARTIN-JONES, Marilyn; MARTIN, Deirdre. Researching multilingualism: critical and ethnographic perspectives. New York: Routledge, 2017. p. 172-185

LEPPÄNEN, Sirpa; KYTÖLÄ, Samu. Investigating multilingualism and multisemioticity as communicative resources in social media. In: MARTINJONES, Marilyn; MARTIN, Deirdre. Researching multilingualism: critical and ethnographic perspectives. New York: Routledge, 2017. p. 155-171

MILROY, James. Ideologias linguísticas e as consequências da padronização. Tradução de Marcos Bagno. In: LAGARES, Xoán; BAGNO, Marcos. (Org.). Políticas da norma e conflitos linguísticos. São Paulo: Parábola Editorial, 2011. p. 49-86.

PINTO, Joana Plaza. Corpos em trânsito, metapragmáticas e ideologias linguísticas na migração estudantil para o Brasil. Projeto de pesquisa. 2016. 29 f. Projeto de Pesquisa, Faculdade de Letras, Universidade Federal de Goiás, Goiânia. 2016.

PINTO, Joana Plaza. Modernidade e diferença colonial nos discursos hegemônicos sobre língua no Brasil. Muitas Vozes, Ponta Grossa, v.1, n.2, p. 171-180, 2012.

POLIVANOC, Beatriz. Etnografia virtual, netnografia ou apenas etnografia? Implicações dos conceitos. Esferas, v. 2, n. 3, p. 61-71, jul.-dez, 2013.

POVINELLI, Elizabeth. Pragmáticas íntimas: linguagem, subjetividade e gênero. Tradução de Joana Plaza Pinto. Estudos Feministas, v. 24, n. 1, p. 205-237, 2016.

SIGNORINI, Inês. Metapragmáticas da língua em uso: unidades e níveis de análise. In: . Situar a linguagem. São Paulo: Parábola, 2008. p. 117-147.

SILVA, Daniel N. O texto entre a entextualização e a etnografia: um programa jornalístico sobre belezas subalternas e suas múltiplas recontextualizações. Linguagem em (Dis)curso, v. 14, p. 67-84, 2014.

SILVERSTEIN, Michael. Metapragmatic discourse and metapragmatic function. In: LUCY, John (Ed.). Reflexive language, reported speech and metapragmatics. Cambridge: Cambridge University Press, 1993. p. 33-58

SILVERSTEIN, Michael; URBAN, Greg. The Natural History of Discourse. In: - (Ed.) Natural Histories of Discourse. Chicago: Chicago University Press, 1996. p. 1-17.

VERTOVEC, Steven. Super-diversity and its implications. Ethnic and Racial Studies, v. 30, n. 6, p. 1024-1054, 2007.

Recebido em outubro/2018.

Aceito em janeiro/2019. 